\title{
Study on the Embodiment and Application of Chinese Decorative Elements in the Design
}

\author{
Liu Yu \\ Tianjin arts and crafts vocational college, Tianjin 300250, China
}

liuyutj@126.com

Keywords: traditional architecture, decorative elements, modern architectural design, interior design, application

\begin{abstract}
Along with the urbanization and acceleration of globalization, the damage of traditional architectural design in China and urbanization is very serious, many architects have advocated the traditional elements in architectural design, which makes the architectural design not only embody the traditional Chinese characteristics, but also keep in line with the development of the times. This paper discusses the theme of the application of traditional architectural decoration elements in modern architectural design. With the development of the times, the level of interior design in China has also been greatly improved. The current interior design techniques are flexible and diverse, which combine traditional decorative elements with modern interior design to meet the public's needs. This paper analyzes the application of the traditional decorative elements in the modern interior design from several aspects.
\end{abstract}

\section{Several Obvious Features of the Traditional Decorative Style}

The Chinese nation has a long history and a well-deserved cultural country. The ancient civilization makes Chinese traditional decorative art rich and colorful, and has distinctive national characteristics. Its history can be traced back to Neolithic, so far, it has created various decorative elements, and has a certain meaning, showing a unique traditional style and creative spirit, which is rare in the history of world decoration. Chinese traditional decorative elements contain rich social connotations. In today's society, decorative elements must reflect the regional and humane care and pay attention to people's spiritual pursuit at a higher level. Obviously some characteristics of Chinese style are: the first is the interior decoration layout, with the axis division, primary and secondary obvious functional layout to traditional customs as the basis; second is to pay attention to the overall tone shading combined with more lines, founder, board do engraving, without losing the appearance of tough, soft feeling; the furniture accessories antique wood, stone, jade, jewelry with gold, porcelain, antiques, paintings, ancient musical instruments should be clear Chinese style decoration typical China traditional furnishings, including painting, calligraphy and painting, plaque hanging, bonsai, porcelain, antiques, screen, shelf, pursue a kind of self-cultivation the realm of life. The characteristics of decorative art Chinese traditional interior is the overall layout of the symmetric equilibrium, good robust, and in the decorative details advocate natural taste, birds, fish and insects and other crafted, full of changes, fully embodies the spirit of traditional aesthetics Chinese.

\section{The Cultural Connotation of the Traditional Ornamental Elements}

Traditional decorative elements are products of cultural development. They contain some mainstream cultures in Chinese history. Their cultural elements include totem worship, haste to avoid disasters, harmony between man and nature, and the doctrine of the mean. In the development of traditional decorative elements, decorative elements of totem worship is Chinese nation for thousands of years. Dragon and Phoenix are the main totem of our country, which are created by people according to their own expectations. The dragon is the totem of the Chinese nation, it 
symbolized the beginning of Chinese culture, such as "dragon and phoenix" is the dominant China traditional decoration pattern development. The Phoenix is the protector of the primitive society, which symbolizes happiness and auspiciousness, and is the most beautiful animal in the birds. Dragon and phoenix patterns are unique traditional decorative elements in our country. In modern interior design art, they express their unique artistic charm with vivid lines. Fly dragon Fengwu, meaning the happy couple, often used for decorative decoration in the wedding room. Also like "Kirin send books" is also our favorite decorative elements, become the spiritual life of the people.

In interior decoration art, often with Kat disaster to people yearning for good luck. There are eight auspicious auspicious signs Kyrgyzstan, and eight diagrams in the myth of the gods. The combination of lotus and fish is the "annual surplus". These decorative themes are closely related to life, and they are the people's yearning for a better life. Has an important effect on Chinese in the tradition of "harmony" of the use of traditional decorative elements. As in a building in Phoenix decorative roof, with a rich spiritual connotation, is the idea of "heaven" performance. The Chinese people, in line with the idea of "harmony between heaven and man", carry out production and life. In the decoration and costumes of the folk houses, the Chinese people all embody it everywhere. As the traditional decorative elements in the water ripples, fire lines, clouds is the natural scene of a kind of application, such as money, it marks the velvet glove, meaning "triangle", which shows people desire to live in harmony with nature. Stressed that a middle course of human and nature, society and human harmony.

\section{The Application of Traditional Decorative Elements in Modern Interior Design}

The application of traditional decorative style in modern interior design. With the development of social economy, the public began to pursue a harmonious and comfortable living space. In order to meet the public's pursuit of space perfection, interior designers will choose different styles of interior design. China's traditional culture has a long history. In the development, it has gradually formed a very strong decorative art, which has a great impact on modern interior design. People pursue more and more natural life space. Designers begin to turn their attention to traditional decorative elements, combine these traditional elements with modern interior design, create ancient style of decoration, and show national cultural atmosphere. It is mainly based on the traditional decorative symbols, decorative patterns and ethnic coloured drawing, etc., and based on this innovation, the interior space is full of retro feeling. On the basis of traditional culture, it absorbs the essence of traditional decorative elements, so as to create a new interior design style, giving people a sense of combination of traditional culture and modern sense. During the interior design, we should combine the preferences of the owners, because retro elements are the styles pursued by many young people. They can combine traditional decorative elements with modern construction, and create excellent works with imagination.

The application of classic basic patterns in modern interior design. In interior design, classical basic patterns are often used, such as noble and auspicious dragon and phoenix patterns, beautiful shapes, and beautiful geometric patterns. With the rapid development of science and technology, the interior design must meet the needs of the times, although it brings people different psychological feelings. But the fine culture of the nation still embodies the characteristics of the traditional culture and represents people's yearning for a better life. For example, the use of Beijing's famous "Pangu" air quadrangles of dragon and phoenix patterns, with the design of the combination of Chinese and western, which is the auspicious clouds dragon room carpet printing patterns, as well as the Dragon Candlestick, noble temperament. Again, in the modern interior design, geometric patterns in water ripples, ice cracks, word lines, such as the use of more paper. Water ripple large area background wall decoration, can enter into a wide open space, like state, consistent with the individual characteristics of the modern pursuit of concise artistic conception. Again, the ice crack is different from modern art, but a messy law reflects some regional spirit, pay attention to reflect the rhythm and the rhythm in the complex, increase the level and pattern of the connotation, so in the modern interior design, decorative parts is extremely rich, especially widely used, it can follow the feeling of space, display the effect is different, the ceiling, partition, background wall is designed to be 
complementary, and partly hidden and partly visible space effect. The application of traditional furniture in modern interior design. Chinese traditional furniture form is more, each kind of meaning is not the same, has a unique flavor.

\section{Analysis of the Elements of Traditional Architectural Decoration}

Painting, sculpture, components are commonly used traditional architectural decorative elements, these elements using the theme are fish and insects, birds, animals, birds, figures etc. The characteristics of the traditional decorative elements theme for the pattern must have its own meaning, it expressed the meaning must be auspicious, the theme has been focusing on the disadvantages and auspicious. The folk artists are full of sex and flexibility in combination of the theme of the random arrangement, the borrowed folk tales or some natural images symbolic and homophonic, through the theme settings direct communication of human emotion, will highlight the theme, aspirations behind the transmission form and the folk aesthetic situation to people. For example, through the full expression of the meaning of the goldfish pattern. Under certain historical conditions, people pursue their pursuit of auspiciousness, happiness and happiness in sculptures and coloured drawing elements, so as to embody traditional culture and folklore in architecture. Coloured drawing is to strengthen the effect of decorative patterns drawn on building components through the use of colors, so as to extend the service life of building components, and embody people's individuality and love for life. Multi use building painting in brackets, QT, doors, window frames, stigma and Liang Fang building wood pieces. The formation of traditional architectural style Chinese largely depends on the architectural sculpture, architectural sculpture to meet people's aesthetic requirements and a certain function in building, brick, stone and wood carvings to three, its main form. In the ancient architectural sculpture, carving can be said to be a kind of art form, its carving pattern mainly for flowers, landscapes and figures, people with good wishes and desire are included in the carving pattern. Zhaobi, gate, houses, tombs and temple walls and is the main component of local brick appear, symbols and patterns of carp, bamboo, chrysanthemum, lotus, camellia, pine, orchid, kylin Songzi, lion, hydrangea, roll The spring comes in full form. auspicious birthday, Guo Ziyi Phoenix are the main theme of the artistic treatment, not only has the good the effect also has a very strong ornamental value. The art of carving a variety of images and patterns on the stone by people's own thoughts and wishes is stone carving. In the traditional architecture, stone used in stone, stone, stone table, China base, Shishi, drum stone, step building components. In traditional architecture, wood carving is its skeleton form. After carving and processing wood and other materials, the specific aesthetic meaning and functional characteristics are expressed. Wood in the rafters, Fang, Tan, beam and column construction of affiliated application, the gorgeous rich and elegant style show. According to the classification process can be divided into wood carvings, reliefs, decorative carvings round is mainly used for main components of Zagreb traction, column arch, purlin, eaves, brackets, Liang Jia, column, relief is used above the courtyard surrounding eaves and railings etc.

\subsection{The Expression Method of Traditional Architectural Decoration Elements in Modern Architectural Design}

Often refer directly to the simple pattern and beautiful composition in the application of the traditional architectural decorative elements, and with modern aesthetic match, for example in the landscape and architecture in the teahouse direct reference to geometric pattern and Dragon carving etc. Shenzhen Vanke fifth garden will be directly applied to the design of auspicious pattern cornices, window, wall, so the traditional Jiangnan Institute, rural water and other characteristics are manifested in the building. The abstract variation of elements is to sculpt and charm the figures by exaggerating, simplifying and so on, and change their structure and proportion, and enhance their theme, so that their image characteristics become more vivid and distinct. Usually refer to abstract variation elements in brackets, pane, the Chinese charm in modern loft with structure, through the well-proportioned square window will traditional culture and modern sense embodied in the construction of. When designing a museum, it can reflect traditional architectural decoration 
elements in the design of the window panes, and form the changing and winding panes through the way of abstract variation, so that they have the modern beauty, so that the buildings contain both the use function and the aesthetic feeling. The displaced and displaced architectural decoration elements are decomposed and reorganized, and can be carried out according to certain rules when they are reassembled. In the process of decomposition, we should decompose it in a free and regular way through specific, approximate, repetitive, rhythmic and rhythmic, harmonic and contrasting, balanced and symmetrical forms and techniques.

\subsection{The Application of Traditional Architectural Decoration Elements in Modern Architectural Design}

As the essence of traditional culture, traditional architectural decoration elements contain deep national cultural atmosphere. People in the process of labor production form the content of traditional architectural decoration, which contains people's yearning for a better life. The process of modern architectural design, decorative elements should be Abstract traditional buildings, and building their own cultural characteristics of the combination, the traditional architectural symbols in architectural works that reflect the image, the charm of traditional architecture in modern architecture, and show modern breath. The Xiangshan Hotel, designed by Mr. Ieoh Ming Pei, a master of architectural design, combines modern garden art and Chinese classical architectural art. Mr. Ieoh Ming Pei combines decorative elements of modern architectural form and traditional courtyard buildings, Jiangnan in the design, using the art processing technique of decomposition and combination of abstract variation of elements, which not only to Chinese traditional architecture psychology, consciousness and the concept of culture was that of Western Gothic architecture is characterized by absorption things, the cultural atmosphere and traditional architectural decorative elements displayed in building [4]. The goal of the Chinese people's life is to pursue good, happy and aspirations. The Xiangshan Hotel embodies this point well in the layout and form of the architecture. The side window shape Xiangshan Hotel is decorated with the diamond pattern, beast and gull kiss, an expression of peace, auspicious concept, staircase column and wall cube use animal pattern, which will be the harmony between man and nature as well as the construction of the artistic conception out. The Museum of Suzhou, which is located near Zhong Wang Fu and near the Humble Administrator's Garden, reflects the traditional architectural style of Suzhou. There is a large area of water between the museum and the museum, which makes the surrounding environment connect with the buildings. The use of design between the pavilion and the courtyard is a modern steel structure, in the landscape design with the Western Gothic gardening style combination of gardening from the traditional ideas, will set up a white background for the wooden frame, the traditional fusion mechanism, will give its natural landscape color, the color coordination, make the surrounding building a more harmonious. The auspicious patterns are engraved on the architectural accessories and wooden windows to highlight the regional culture and the traditional features. Through the opening of skylight and mortise and tenon structure, the use of radiation and introduction of light, so as to facilitate the control of the light in the building, make it more soft.

\section{Conclusions}

In performance and application of China traditional decorative elements in the thousands of years of development history of interior design aesthetic value and design concept plays an important role. Especially for the design and development trend of contemporary indoor space environment, we should further develop along with the development of the times and the progress of society, as well as the improvement of people's spiritual and material life level. In this paper, the use of traditional architectural elements in the modern architectural design are discussed, firstly analyzes the traditional architectural elements, then introduces the methods of expression of traditional architectural elements in the modern architectural design, finally illustrates the use of traditional architectural elements in the modern architectural design. Our traditional architectural design elements have a long history. As an artistic treatment of building additional components, decoration has inherited our excellent architectural culture. Therefore, in the development of 
construction industry, we should make more use of traditional architectural elements, so that modern buildings contain distinctive traditional architectural elements, and carry forward and inherit the spirit of Chinese traditional culture.

\section{References}

[1] Y.B, Y.S. Inheritance and Innovation -- Analysis of China traditional architectural elements in the modern architectural design of the application of [J]. architecture and culture, 2013,08:55-56.

[2] Z.Y.M, J.L. On the China traditional architectural decoration application in modern landscape design [J]. Journal of HeFei University of Technology (SOCIAL SCIENCE EDITION), 2013,02:76-80.

[3] Y.B, Y.S. Inheritance and Innovation -- Analysis of China traditional architectural elements in the modern architectural design of the application of [J]. architecture and culture, 2013,08:55-56.

[4] Red, our forum for research on Application of [J]. for Zhiqiang. China traditional architectural elements in modern landscape architecture design in the (second half), 2013,03:100-101.

[5] X.L, M.C.Y. The application of traditional Chinese decorative elements in modern interior design [J]. popular literature and art, 2012 (19). 